\title{
Long non-coding RNA GHET1 promotes osteosarcoma development and progression via Wnt/ß-catenin signaling pathway
}

\author{
XINGLI CHEN $^{1}$, WEI ZHAO ${ }^{2}$ and WEIMIN FAN ${ }^{2}$ \\ ${ }^{1}$ Department of Orthopedics, The Affiliated Huai'an Hospital of Xuzhou Medical University and The Second People's \\ Hospital of Huai'an, Huaian, Jiangsu 223002; ${ }^{2}$ Department of Clinical Laboratory, Women's Hospital of Nanjing \\ Medical University (Nanjing Maternity and Child Health Care Hospital), Nanjing, Jiangsu 210004, P.R. China
}

Received June 6, 2019; Accepted January 16, 2020

DOI: $10.3892 /$ or.2020.7585

\begin{abstract}
Osteosarcoma (OS) is known as a malignant tumor with a high mortality rate of children and adults worldwide. Long non-coding RNAs (IncRNAs) have been revealed as oncogenes or tumor suppressors that are involved in the tumorigenesis and metastasis of some types of cancer. However, the biological role of long non-coding RNA gastric carcinoma proliferation enhancing transcript 1 (IncGHET1) and its regulatory mechanism in OS progression have not been elucidated. The aim of the present study was to investigate the role of IncGHET1 in OS. The present study explored lncGHET1 expression using a reverse transcription-quantitative (RT-q) PCR assay. Furthermore, the Cell Counting Kit-8 assay, flow cytometry detection, wound healing and transwell invasion assays were performed to evaluate its biological role and the underlying mechanisms in vitro. Additionally, the effect of lncGHET1 was evaluated in vivo in a xenograft model. IncGHET1 expression was significantly upregulated in OS cell lines compared with in an osteoblastic cell line according to the RT-qPCR assay. The results of a knockdown functional experiment suggested that inhibition of lncGHET1 attenuated cell proliferation, migration, invasion and epithelial-to-mesenchymal transition, and promoted apoptosis, partly through regulating the $\mathrm{Wnt} / \beta$-catenin signaling pathway in OS. These findings indicated that lncGHET1 may serve an essential regulatory role in the biological processes of OS. The present study identified a novel therapeutic target for diagnosis and treatment of human OS.
\end{abstract}

Correspondence to: Dr Weimin Fan, Department of Clinical Laboratory, Women's Hospital of Nanjing Medical University (Nanjing Maternity and Child Health Care Hospital), 123 Mochou Road, Nanjing, Jiangsu 210004, P.R. China

E-mail: fanweimin1211@163.com

Key words: long non-coding RNA gastric carcinoma proliferation enhancing transcript 1 , proliferation, migration, invasion, epithelialto-mesenchymal transition, Wnt/ $\beta$-catenin pathway, osteosarcoma

\section{Introduction}

Osteosarcoma (OS) is a primary malignant bone tumor that typically affects the long tubular bones of children and adults worldwide (1). OS is characterized by the direct formation of immature bone or osteoid tissue by tumor cells (2), as well as poor prognosis $(3,4)$. Despite medical advances and development of early diagnosis, the prognosis of patients with metastatic osteosarcoma remains poor, with a cure rate of $\sim 30 \%$ (5-7). OS remains a leading cause of cancer-associated mortality among children and teenagers (8-10). Therefore, it is urgently necessary to develop novel targets and research the underlying mechanisms of bone carcinogenesis, which is critical for the treatment and prognosis of OS in the future.

Long non-coding RNAs (lncRNAs) are sequences $>200 \mathrm{nt}$ in length and without protein-coding capacity (11). Previous studies have provided evidence that IncRNAs serve significant roles in the biological behavior of tumors, including proliferation, invasion, metastasis, differentiation and apoptosis (12-15). Notably, a previous study has confirmed the dysregulation of IncRNAs in human OS (16). IncRNA FGFR3-AS1 promotes OS growth by regulating fibroblast growth factor receptor 3 (17). In addition, lncRNA small nucleolar RNA host gene 12 promotes OS cell proliferation and migration in vitro (18). Therefore, further investigations are required to evaluate the expression pattern, biological role and functional mechanisms of lncRNAs in OS. Long non-coding RNA gastric carcinoma proliferation enhancing transcript 1 (lncGHET1; AK123072) has been demonstrated to be abnormally expressed in gastric, bladder and colorectal cancer (19-22). However, the role and underlying mechanisms of lncGHET1 in OS remain unclear.

The present study analyzed the lncGHET1 expression pattern in OS cell lines using reverse transcription-quantitative PCR (RT-qPCR). In addition, loss-of-function experiments were performed to investigate the biological roles of lncGHET1 in OS. The results revealed that lncGHET1 expression was upregulated in OS cell lines. Additionally, the results of in vitro and in vivo assays revealed that silenced lncGHET1 inhibited cell proliferation, tumor growth, migration, invasion and epithelialto-mesenchymal transition (EMT), and promoted apoptosis, partly via the $\mathrm{Wnt} / \beta$-catenin signaling pathway. The findings suggested that lncGHET1 functions as an oncogene, which may contribute to the development for diagnosis and treatment of OS. 


\section{Materials and methods}

Cell culture and transfection. Human OS U2OS, MG-63 and $\mathrm{SaOs}-2$ cell lines, and the epithelial hFOB cell line were purchased from American Type Culture Collection. All cells were cultured in RPMI-1640 medium (Invitrogen; Thermo Fisher Scientific, Inc.) supplemented with 10\% FBS (Gibco; Thermo Fisher Scientific, Inc.) and $100 \mathrm{U} / \mathrm{ml}$ penicillin and streptomycin (Thermo Fisher Scientific, Inc.) and maintained at $37^{\circ} \mathrm{C}$ with $5 \% \mathrm{CO}_{2}$. Small interfering RNA (si/siRNA)-IncGHET1 (5'-CGGCAGGCATTAGAGATGAAC AGCA-3') and negative control (si-NC) (5'-CGGCAGGCA UUAGAGAUGAACAGCA-3') were designed and synthesized by Shanghai GenePharma Co., Ltd. For cell transfection, $50 \mathrm{nM}$ siRNA or si-NC was transfected into U2OS and MG-63 cells $\left(1 \times 10^{6}\right)$ using Lipofectamine ${ }^{\circledR} 2000$ (Invitrogen; Thermo Fisher Scientific, Inc.) according to the manufacturer's protocol. After $48 \mathrm{~h}$, the cells were collected for further experimentation. The transfection efficiency was evaluated by GFP and RT-qPCR analyses.

Cell Counting Kit-8 (CCK-8) assay. A CCK-8 (Sigma-Aldrich; Merck $\mathrm{KGaA}$ ) assay was performed to examine cell viability according to the manufacturer's protocol. Briefly, MG-63 and U2OS cells were seeded at a density of $1 \times 10^{4}$ per well and incubated in a humidified incubator at $37^{\circ} \mathrm{C}$ for 24,48 and $72 \mathrm{~h}$. Subsequently, the cells were incubated with $10 \mu \mathrm{l} \mathrm{CCK}-8$ solution for another $2 \mathrm{~h}$ at $37^{\circ} \mathrm{C}$. Optical density was determined at a wavelength of $450 \mathrm{~nm}$.

Colony formation and 5-ethynyl-20-deoxyuridine (EdU) assay. For the colony formation assay, transfected cells $(1,000$ cells/well) were seeded and cultured for 14 days. Subsequently, the cells were fixed with $4 \%$ polyoxymethylene for $20 \mathrm{~min}$ at room temperature and stained with $10 \%$ crystal violet for $30 \mathrm{~min}$ at room temperature. The colonies were counted and analyzed under a light microscope. For the EdU assay, $1 \times 10^{6}$ transfected cells were seeded and cultured for $24 \mathrm{~h}$, and then fixed with $4 \%$ paraformaldehyde at room temperature for $15 \mathrm{~min}$, followed by $100 \mu 1 \mathrm{1X}$ Hoechst $33342(5 \mu \mathrm{g} / \mathrm{ml})$ staining for $30 \mathrm{~min}$ at room temperature. Cells were visualized under a fluorescence microscope (Leica Microsystems $\mathrm{GmbH}$ ).

RT-qPCR analysis. Total RNAs from U2OS and MG-63 cells with different treatments were extracted using TRIzol ${ }^{\circledR}$ reagent (Invitrogen; Thermo Fisher Scientific, Inc.) according to the manufacturer's protocol. Reverse transcription was performed with SuperScriptTM II reverse transcriptase (Invitrogen; Thermo Fisher Scientific, Inc.). The protocol was as follows: $42^{\circ} \mathrm{C}$ for $60 \mathrm{~min}, 70^{\circ} \mathrm{C}$ for $15 \mathrm{~min}$ and chilling at $4^{\circ} \mathrm{C}$. The relative levels of genes were detected by RT-qPCR using SYBR Premix Ex Taq ${ }^{\mathrm{TM}}$ (Takara Bio, Inc.). PCR cycling conditions were as follows: $95^{\circ} \mathrm{C}$ for $5 \mathrm{~min}$, followed by denaturation for $10 \mathrm{sec}$ at $95^{\circ} \mathrm{C}$ and extension for $30 \mathrm{sec}$ at $60^{\circ} \mathrm{C}$ for 40 cycles, and $60^{\circ} \mathrm{C}$ for $5 \mathrm{~min}$. GAPDH was used as an internal loading control. All reactions were performed in triplicate. Fold changes were calculated using the $2^{-\Delta \Delta C q}$ method (23). The primers were as follows: GHET1 forward, 5'-CCCCACAAATGAAGACACT-3' and reverse, 5'-TTC CCAACACCCTATAAGAT-3'; snail forward, 5'-TGTTGC
AGTGAGGGCAAGAA-3' and reverse, 5'-GACCCTGGT TGCTTCAAGGA-3'; N-cadherin forward, 5'-CGAGCCGCC TGCGCTGCCAC-3' and reverse, 5'-CGCTGCTCTCCGCTC CCCGC-3'; E-cadherin forward, 5'-TACGCCTGGGACTCC ACCTA-3' and reverse, 5'-CCAGAAACGGAGGCCTGAT-3'; vimentin forward, 5'-TACAGGAAGCTGCTGGAAGG-3' and reverse, 5'-ACCAGAGGGAGTGAATCCAG-3'; and GAPDH forward, 5'-CGGAGTCAACGGATTTGGTCGTAT-3' and reverse, 5'-AGCCTTCTCCATGGTGGTGAAGAC-3'.

Western blot analysis. Total proteins were extracted using RIPA buffer (Cell Signaling Technology, Inc.) and the protein concentrations were determined using the BCA Protein Assay kit (Beyotime Institute of Biotechnology). Proteins (30 $\mu \mathrm{g} / \mathrm{lane})$ were separated by $10 \%$ SDS-PAGE and transferred to PVDF membranes (EMD Millipore). Membranes were blocked with $5 \%$ non-fat milk for $2 \mathrm{~h}$ at room temperature. Subsequently, the membranes were incubated with primary antibody at $4^{\circ} \mathrm{C}$ overnight. After washing with TBS with $1 \%$ Tween-20, the membranes were probed with HRP-conjugated rabbit anti-mouse $\mathrm{IgG}$ secondary antibodies (cat. nos. ab6721 and ab6728; dilution, 1:5,000; Abcam) for $1 \mathrm{~h}$ at room temperature. GAPDH was used as a loading control. The protein bands were visualized using an Enhanced Chemiluminescence Detection system (Thermo Fisher Scientific, Inc.). The data were analyzed using Image-Pro plus software v6.0 (National Institutes of Health). Antibodies for p21 (cat. no. 64016; dilution, 1:1,000), p27 (cat. no. 3688; dilution, 1:2,000), cyclin D1 (cat. no. 55506; dilution, 1:2,000), GAPDH (cat. no. 5174; dilution, 1:5,000), Bax (cat. no. 2772; dilution, 1:2,000), Bcl-2 (cat. no. 3498; dilution, 1:2,000), caspase-3 (cat. no. 9664; dilution, 1:1,000), caspase-9 (cat. no. 9509; dilution, 1:2,000) and MMP-2 (cat. no. 87809; dilution, 1:1,000) were purchased from Cell Signaling Technology, Inc. Antibodies for MMP-9 (cat. no. ab38898; dilution, 1:2,000), Snail (cat. no. ab53519; dilution, 1:2,000), N-cadherin (cat. no. ab18203; dilution, 1:2,000), E-cadherin (cat. no. ab231303; dilution, 1:2,000), vimentin (cat. no. ab92547; dilution, 1:1,000), Wnt (cat. no. ab219412; dilution, 1:1,000) and $\beta$-catenin (cat. no. ab16051; dilution, 1:1,000). All of these antibodies were purchased from Abcam.

Wound healing assay. In order to evaluate the role of IncGHET1 in migration of OS cells, $1 \times 10^{6}$ MG-63 and U2OS cells were seeded in a 6 -well plate, and $2 \mathrm{ml}$ culture medium supplemented with $10 \%$ FBS were added. When cells were grown to $90 \%$ confluence, cells were synchronized in serum-free medium for $24 \mathrm{~h}$, followed by a standard wound $(<3 \mathrm{~mm})$ created on the cell monolayer (time set as $0 \mathrm{~h}$ ). A PBS solution was used to remove floating cells. Subsequently, cells were incubated in fresh complete medium (1\% FBS) for 0,24 and $48 \mathrm{~h}$ and the number of migrated cells was observed and counted under a light microscope. The results were quantified by Image-Pro plus software 6.0 (National Institutes of Health).

Transwell assay. The migration and invasion abilities of MG-63 and U2OS cells were measured using a transwell assay (cat. no. $3422 ; 6.5-\mathrm{mm}$ insert; $8-\mu \mathrm{m}$ polycarbonate membrane; Costar; Corning, Inc.). Briefly, $1 \times 10^{5}$ transfected cells were suspended in serum-free medium and seeded into the upper chamber without (for the migration assay) Matrigel 
A

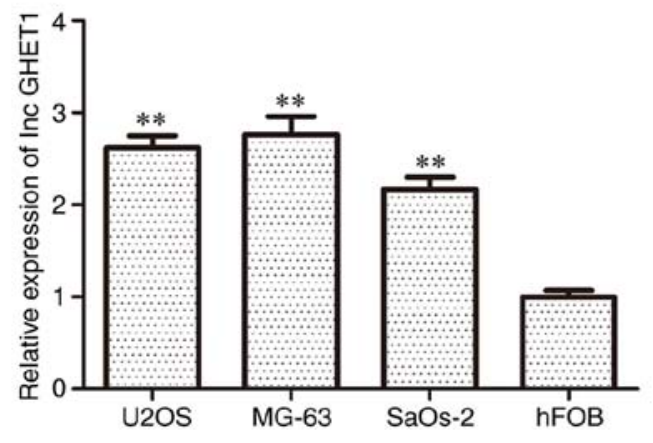

C
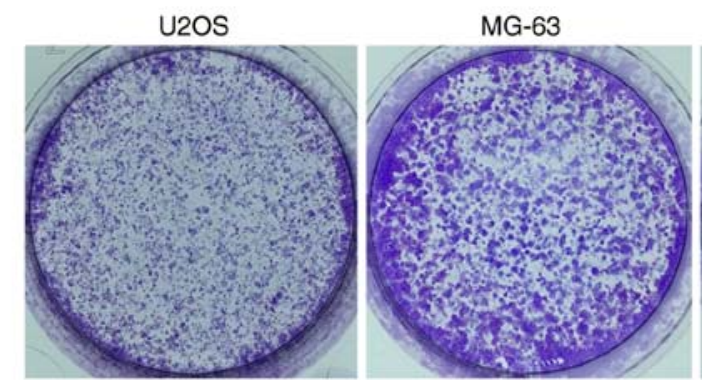

B

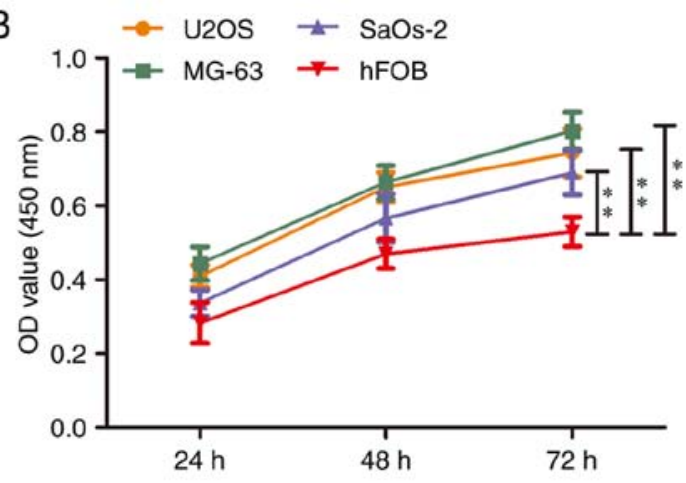

MG-63 SaOs-2

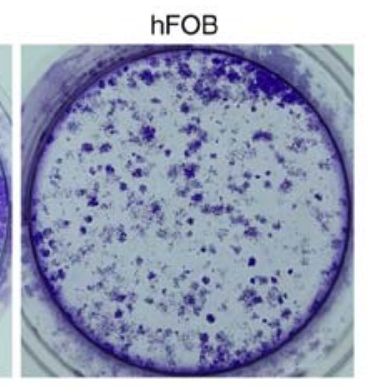

D
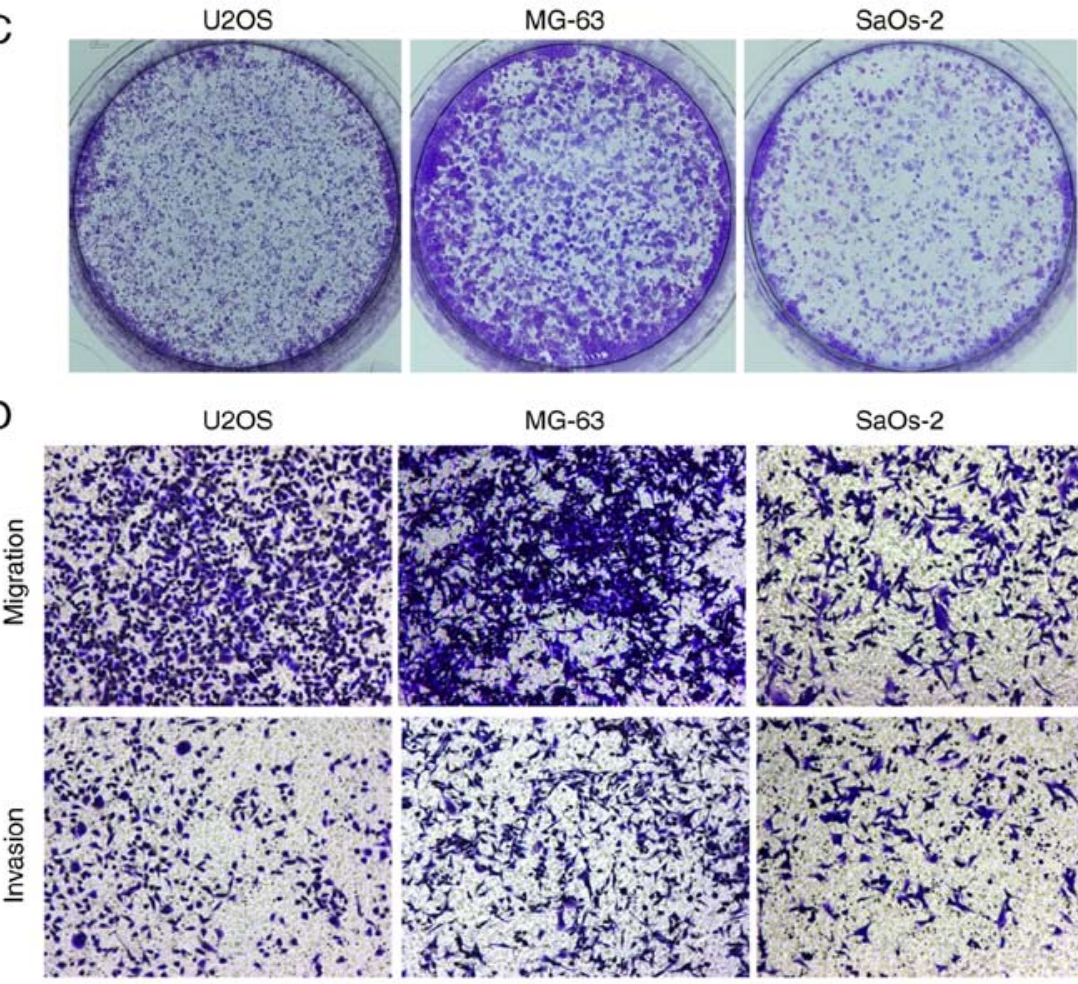

SaOs-2
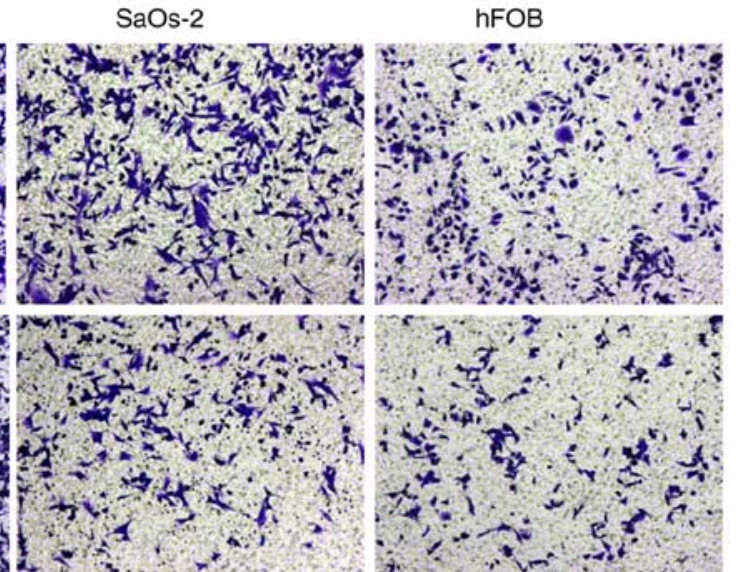

Figure 1. IncGHET1 is upregulated in OS cell lines. (A) Expression levels of lncGHET1 in OS cell lines. ${ }^{* *} \mathrm{P}<0.01$ vs. hFOB group. (B) Cell Counting Kit- 8 and $(\mathrm{C})$ colony formation assays were performed to detect the proliferation ability of cell lines. ${ }^{* *} \mathrm{P}<0.01 \mathrm{vs}$. hFOB group. (D) Cell migration and invasion were assessed by transwell assays. Magnification, x200. lncGHET1, long non-coding RNA gastric carcinoma proliferation enhancing transcript 1; OD, optical density; OS, osteosarcoma.

(BD Biosciences) or with a porous membrane coated with Matrigel (BD Biosciences) (for the transwell invasion assay). The Matrigel was incubated at $37^{\circ} \mathrm{C}$ for $4 \mathrm{~h}$ before testing. Subsequently, serum-free medium was added into the upper chambers. Medium containing $10 \%$ FBS was added into the lower chambers. Following incubation for $48 \mathrm{~h}$, the cells from the upper compartments were scraped off with cotton swabs, whereas the cells that migrated or invaded to the lower surface of the membrane were fixed with $4 \%$ paraformaldehyde at room temperature for $10 \mathrm{~min}$ and stained with $10 \%$ crystal violet at room temperature. The numbers of migrated or invasive cells were counted in five random fields under a light microscope at x200 magnification. Experiments were independently repeated three times.

Cell cycle and apoptosis analyses. The effect of lncGHET1 on cell cycle and apoptosis was evaluated by flow cytometry using the Annexin V Apoptosis Detection kit (BD Biosciences) and the Cell Cycle kit (BD Biosciences). Briefly, for cell cycle analysis, MG-63 and U2OS cells were harvested and washed with cold PBS twice. Following fixation with $70 \%$ ethanol at $4^{\circ} \mathrm{C}$ overnight and labelling with propidium iodide (PI) solution $(0.1 \mu \mathrm{g} / \mu \mathrm{l})$ in the presence of Ribonuclease A (Takara Bio, Inc.) at $37^{\circ} \mathrm{C}$ for $30 \mathrm{~min}$ in the dark, cells were assessed by flow cytometry (FACScan; BD Biosciences). For cell apoptosis analysis, cells were washed with cold PBS twice. Subsequently, cells were incubated with Annexin V-FITC and PI (BD Biosciences) for $15 \mathrm{~min}$ in the dark at room temperature. Finally, cell apoptosis was assessed using flow cytometry (FACScan; BD Biosciences) using FlowJo 10.06 software (FlowJo LLC). The data of these experiments were analyzed by FlowJo v10 software (Tree Star, Inc.).

Xenograft tumors in nude mice. Female BALB/c nude mice (SPF, n=6; age, 6 weeks; weight, 18-22 g) were provided by Nanjing Medical University (Nanjing, China). The mice were 


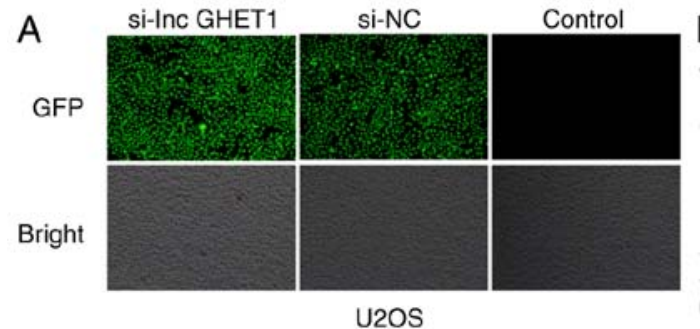

U2OS

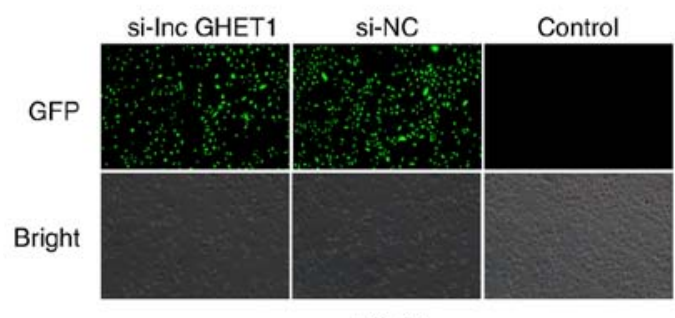

MG-63

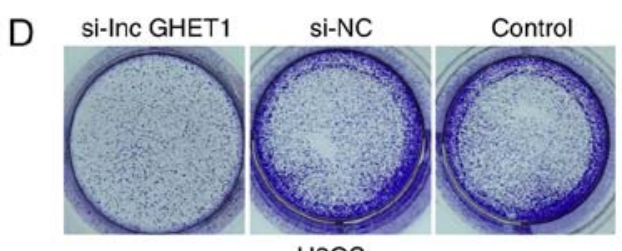

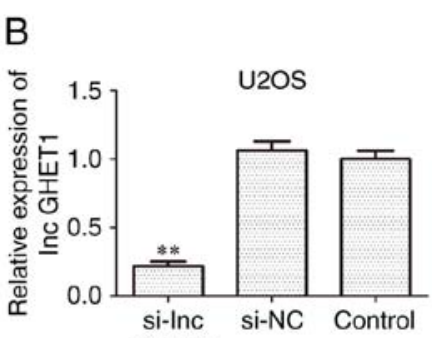

GHET1

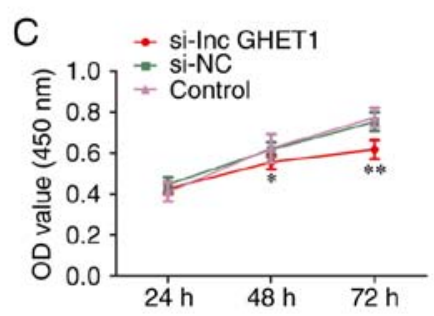

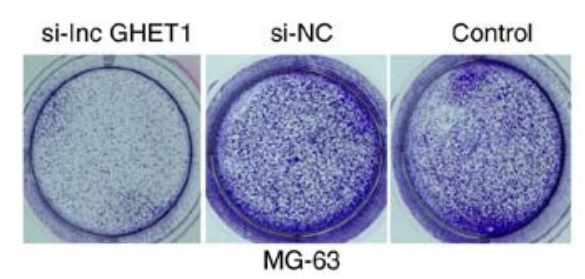

Figure 2. Effects of lncGHET1 on cell proliferation of OS. (A) Transfection efficiency of MG-63 and U2OS cells was assessed by fluorescence microscopy. Magnification, x200. (B) Reverse transcription-quantitative PCR analysis was used to assess the expression levels of 1ncGHET1 in MG-63 and U2OS cells after transfection. (C) Cell proliferation and (D) colony formation in MG-63 and U2OS cells. All data are presented as the mean \pm SD of three independent experiments. ${ }^{*} \mathrm{P}<0.05,{ }^{* *} \mathrm{P}<0.01$ vs. control group. GFP, green fluorescent protein; lncGHET1, long non-coding RNA gastric carcinoma proliferation enhancing transcript 1; NC, negative control; OD, optical density; OS, osteosarcoma; si, small interfering RNA.

housed in 12-h light/dark cycle in a temperature-controlled $\left(22-26^{\circ} \mathrm{C}\right)$ and humidity-controlled $(40-70 \%)$ room with freely accessible chow and tap water. To detect the effect of tumor growth in vivo, $5 \times 10^{5}$ transfected MG-63 and U2OS cells were suspended in PBS and subcutaneously injected into the right flank of nude mice, and the mice of the control group were treated with PBS. Following a 36-day period, nude mice were euthanized by a high dose of anesthesia $(150 \mathrm{mg} / \mathrm{kg}$ pentobarbital; intraperitoneal injection) according to protocols set by the Ethical Committee of the Ethical Committee of Nanjing Medical University (approval no. SYXK(SU)2018-0114). After nude mice were sacrificed, neoplasms were isolated for further analyses. The tumor volumes were recorded by slide calipers every week and calculated using the following formula: Volume $=0.5 \mathrm{x}$ length $\mathrm{x}$ width $\mathrm{x}$ width.

Hematoxylin and eosin $(H \& E)$ staining. The tumor tissues were fixed in $4 \%$ paraformaldehyde at room temperature for $10 \mathrm{~min}$ and then embedded in paraffin. The sections were immersed in $0.5 \%$ hematoxylin for $5 \mathrm{~min}$, followed by staining with $0.5 \%$ eosin solution for $1 \mathrm{~min}$ at room temperature. At least three different sections of tumor tissues were examined for each group using a light microscope to assess the histopathological alterations.

Tunel assay. The in situ Cell Death Detection kit was purchased from Roche Diagnostics. All the steps were preformed according to the manufacturer's protocol. The sections were dewaxed in xylene and hydrated by graded ethanol solution. Samples were fixed in $10 \%$ formalin for $24 \mathrm{~h}$ at $4^{\circ} \mathrm{C}$, embedded in paraffin and assessed using TUNEL staining (Roche Diagnostics $\mathrm{GmbH}$ ) for $1 \mathrm{~h}$ at room temperature according to the manufacturer's protocol. After washing with PBS for several times, sections (5- $\mu \mathrm{m}$ thick) were incubated with $20 \mu \mathrm{g} / \mathrm{ml}$ proteinase $\mathrm{K}$ for $30 \mathrm{~min}$ at $37^{\circ} \mathrm{C}$. Subsequently, the sections were incubated with a terminal deoxynucleotidyl transferase, followed by treatment with 3\% hydrogen peroxide for $5 \mathrm{~min}$. After that, the sections were incubated with peroxidase-conjugated antibody (cat. no. ab197034; dilution, 1:1,000; Abcam) for $10 \mathrm{~min}$ at room temperature. After washing with PBS for several times, the DAB solution with $3 \%$ hydrogen peroxide was added, and the methyl green was added. Finally, the sections were treated with Mayer's hematoxylin. The mounting medium was neutral resin. The images were observed in five fields under a fluorescence microscope.

Statistical analysis. All experiments were performed at least three times. The results are presented as the mean \pm SD. Statistical analyses were performed using SPSS v19.0 software (IBM Corp.). Student's t-test was performed to evaluate significant differences between two independent groups of samples. One-way ANOVA followed by Tukey's post hoc test was applied to compare differences among multiple groups. $\mathrm{P}<0.05$ was considered to indicate a statistically significant difference.

\section{Results}

IncGHET1 is upregulated in OS cell lines. The present study first examined the expression levels of lncGHET1 in the 

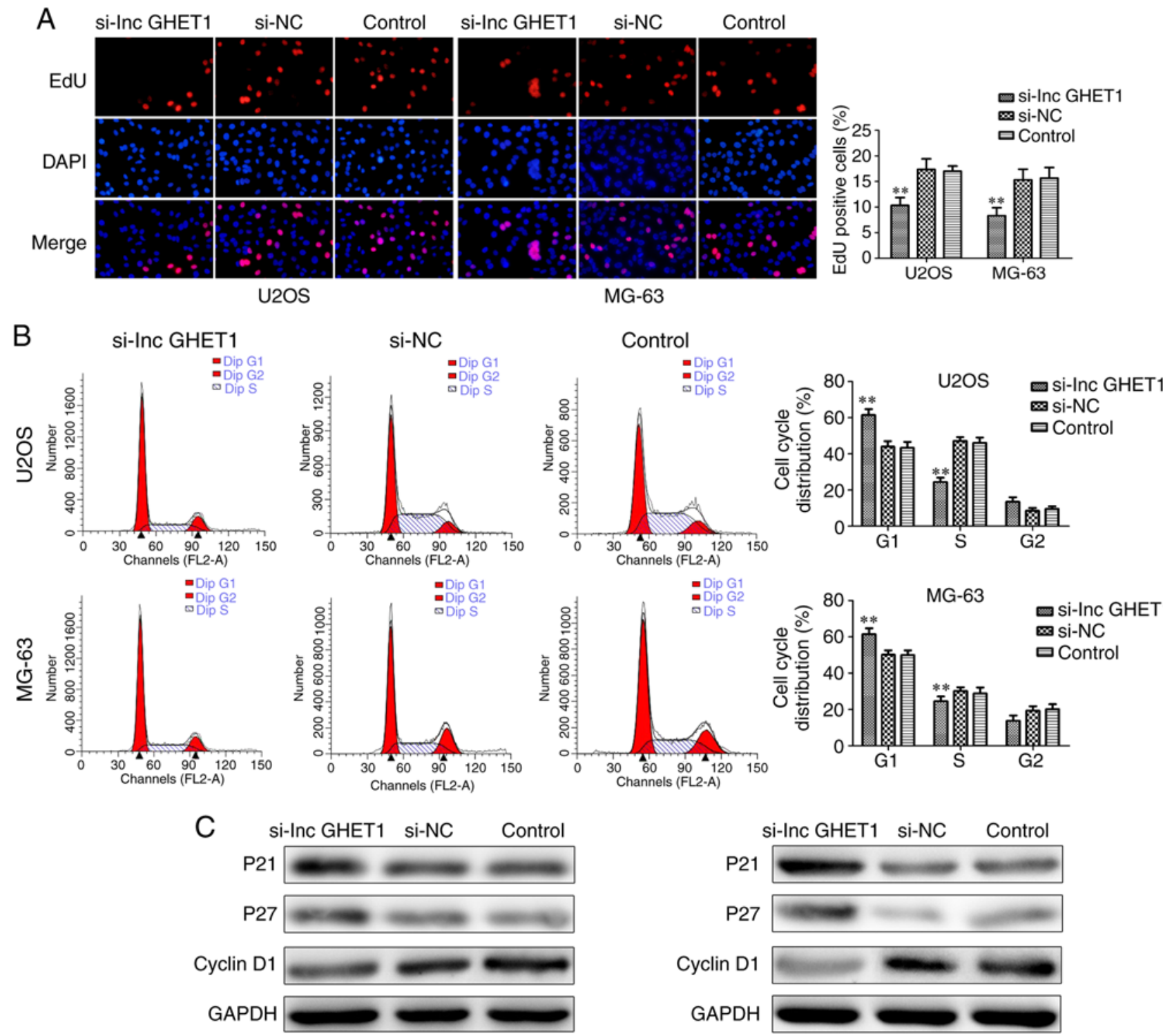

U2OS

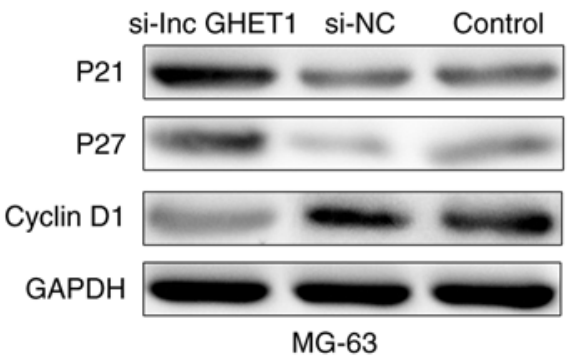

Figure 3. Effect of 1ncGHET1 on the cell cycle. (A) Cell proliferation was detected by EdU assay. (B) Cell cycle was assessed via flow cytometry. (C) Western blot analysis was used to determine the protein levels of cell cycle-related factors. ${ }^{* *} \mathrm{P}<0.01$ vs. control group. EdU, 5-ethynyl-20-deoxyuridine; lncGHET1, long non-coding RNA gastric carcinoma proliferation enhancing transcript 1; NC, negative control; si, small interfering RNA.

U2OS, MG63, SaOs-2 and hFOB cell lines. Compared with the hFOB cell line, lncGHET1 expression was markedly higher in the OS cell lines (Fig. 1A). As shown in Fig. 1B, the cell proliferation abilities of U2OS, SaOs-2 and MG-63 cells were significantly higher than those in the hFOB group at $72 \mathrm{~h}$. Furthermore, colony formation assays showed that there were more colonies in the former three cell lines compared with in the hFOB group (Fig. 1C). In addition, an increased migration and invasion rate was observed in the U2OS, SaOs-2 and MG-63 groups (Fig. 1D). These data indicated that lncGHET1 may function as a regulator of OS progression.

Effects of lncGHET1 on proliferation of OS cells. To assess the role of lncGHET1 in MG-63 and U2OS cell proliferation, siRNA was transfected to silence lncGHET1 expression. Following transfection for $48 \mathrm{~h}$, lncGHET1 expression was detected using fluorescence microscopy and RT-qPCR. As shown in Fig. 2A and B, the results revealed that the siRNA transfection decreased lncGHET1 expression, whereas there was no significant difference observed between the si-NC and control groups. Subsequently, cell proliferation was assessed using CCK-8, colony formation and EdU assays. As demonstrated by the result of the CCK- 8 assay, cell growth was suppressed in MG-63 and U2OS cells which were transfected with si-lncGHET1 compared with the cells transfected with si-NC and the control group (Fig. 2C). In addition, the colony formation ability of si-lncGHET1-transfected cells was decreased (Fig. 2D). An EdU assay was conducted to further confirm the effect of lncGHET1 on OS cells. The results revealed that downregulation of 1ncGHET1 markedly decreased the percentage of EdU-positive cells in MG-63 and U2OS cells (Fig. 3A).

To study the effect of lncGHET1 on the OS cell cycle, flow cytometry was performed. As shown in Fig. 3B, a significantly 
A

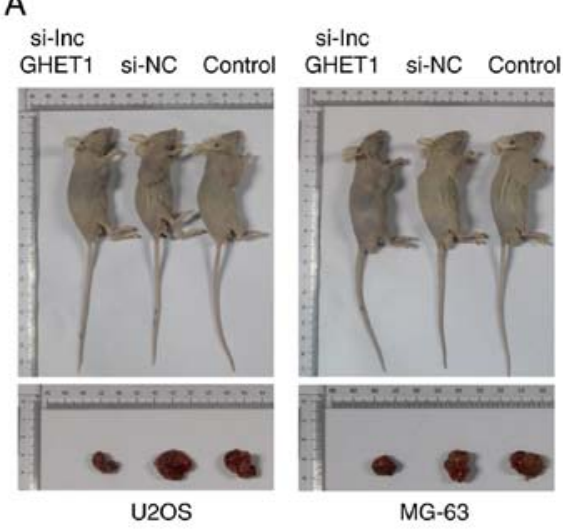

D
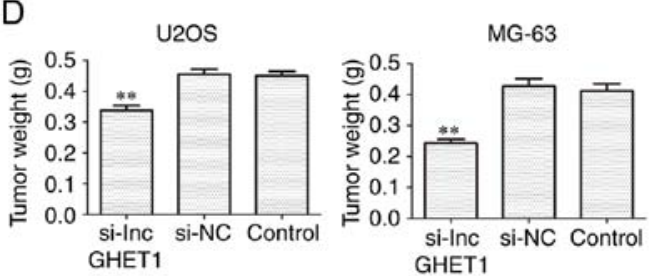

B
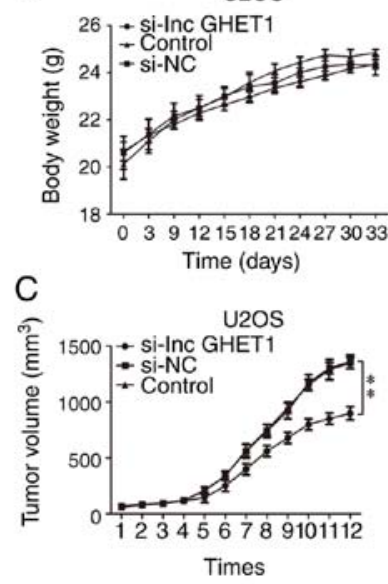

E

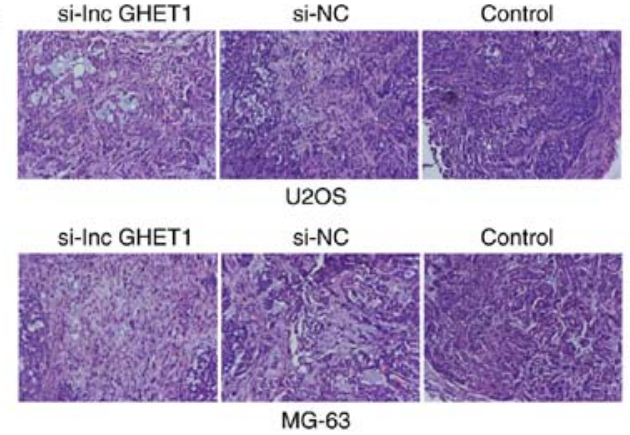

Figure 4. Effect of lncGHET1 on cell growth in vivo. (A) Images of nude mice, (B) bodyweight, (C) tumor volume and (D) tumor weight are shown. The longest and shortest diameters of the tumor size in U2OS infected nude mice were 13.9, 20.1, 19.0 mm; 7.1, 13.4, $12.5 \mathrm{~mm}$, successively. And these parameters of tumor size in the MG-63 infected nude mice were 15.1, 17.2, $20.0 \mathrm{~mm} ; 10.9,11.5,11.3 \mathrm{~mm}$, successively. (E) Hematoxylin and eosin staining was performed and the images were captured at a magnification of $\mathrm{x} 200 .{ }^{* *} \mathrm{P}<0.01 \mathrm{vs}$. control group. IncGHET1, long non-coding RNA gastric carcinoma proliferation enhancing transcript 1; NC, negative control; si, small interfering RNA.

A
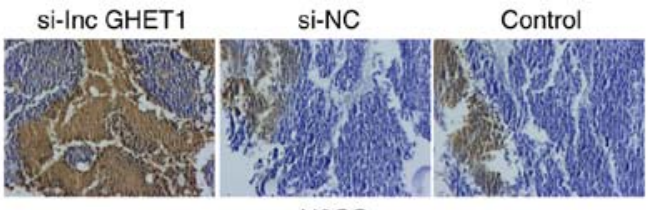

U2OS
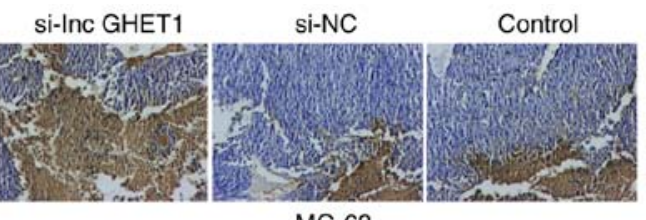

MG-63

B
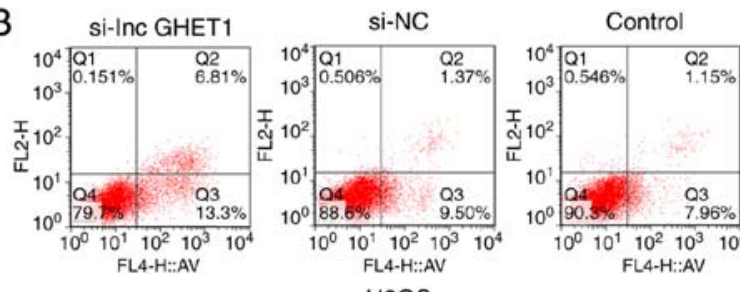

U2OS

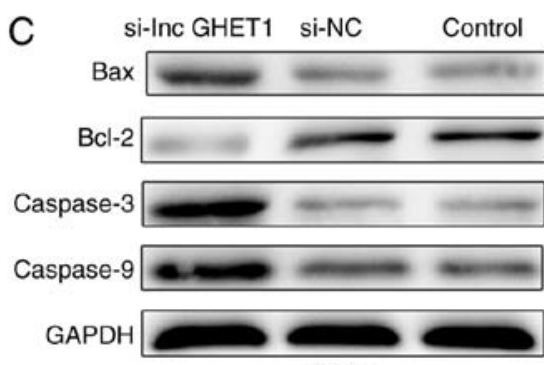

U2OS
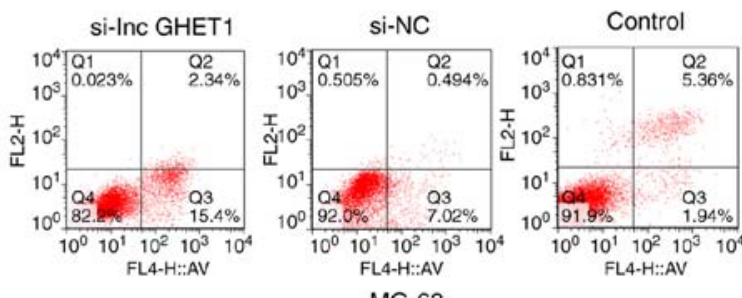

MG-63

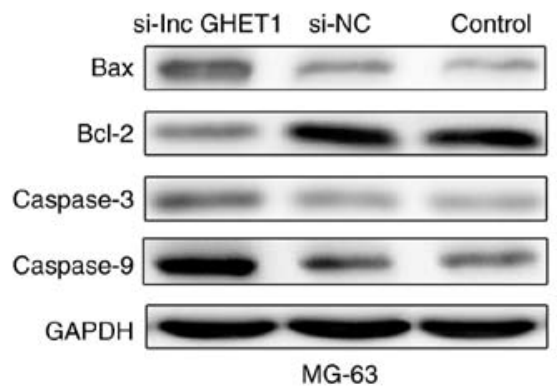

Figure 5. Effect of 1ncGHET1 on cell apoptosis. (A) Apoptosis of tumors was detected using a Tunel assay. Magnification, x200. (B) Apoptosis of MG-63 and U2OS cells was detected using flow cytometric analysis. (C) Key apoptotic players were examined by western blotting. lncGHET1, long non-coding RNA gastric carcinoma proliferation enhancing transcript 1; NC, negative control; si, small interfering RNA. 


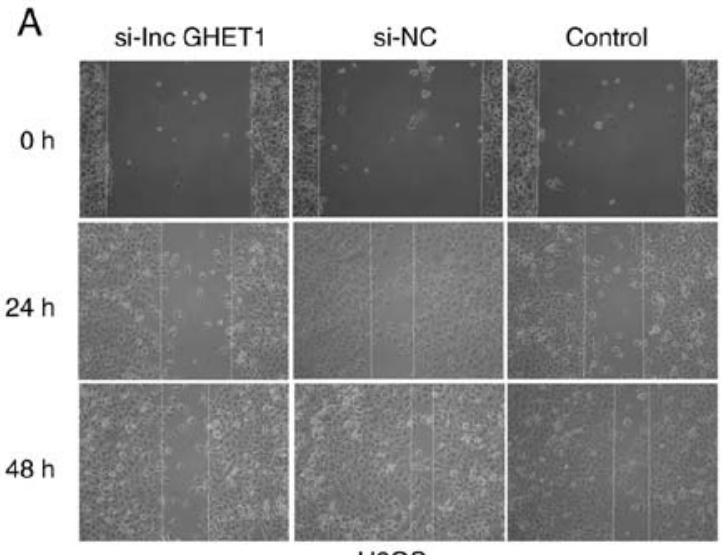

U2OS

B

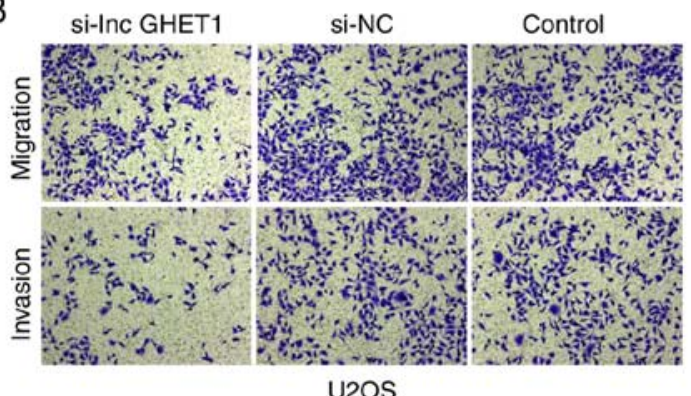

U2OS

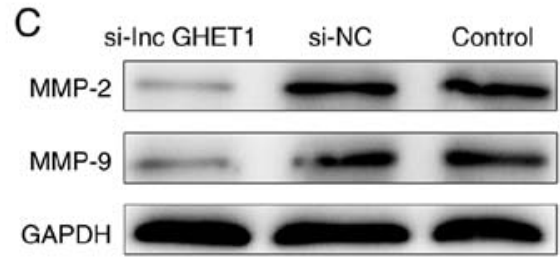

U2OS

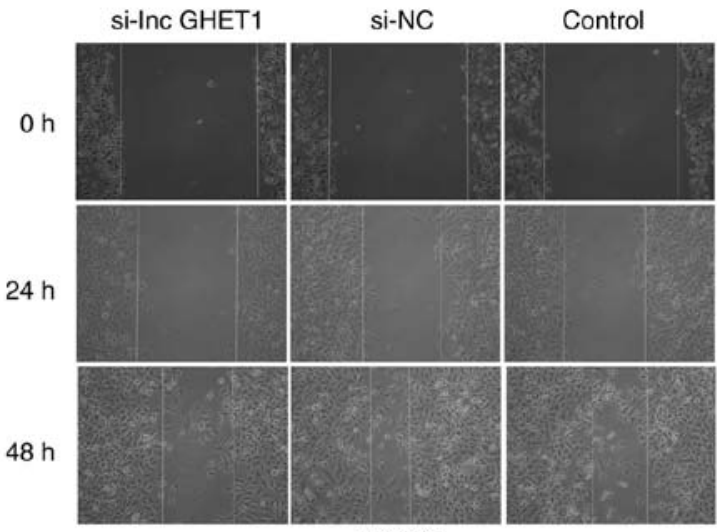

MG-63

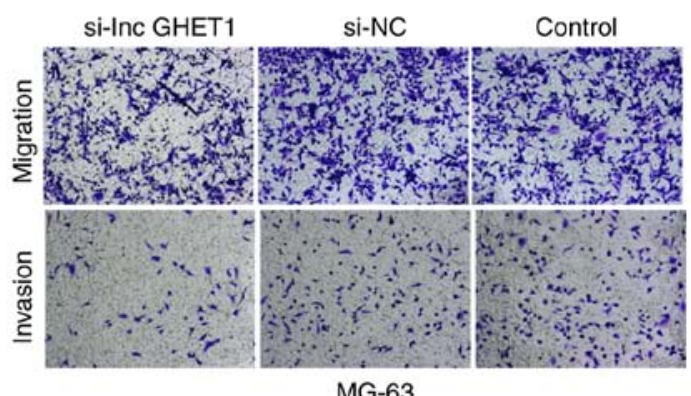

MG-63

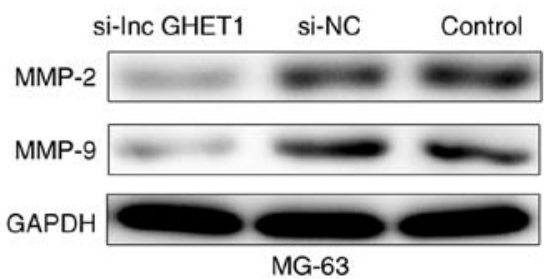

Figure 6. Effect of lncGHET1 on cell migration and invasion. (A) Wound healing assay was performed to detect migration of MG-63 and U2OS cells. (B) Transwell assay was performed to detect migration and invasion of MG-63 and U2OS cells. Magnification, x200. (C) Expression levels of migration and invasion-related proteins (MMP-2 and MMP-9) were detected by western blotting. IncGHET1, long non-coding RNA gastric carcinoma proliferation enhancing transcript 1; MMP, matrix metalloproteinase; NC, negative control; si, small interfering RNA.

greater proportion of $\mathrm{G}_{1}$ phase cells and a markedly lesser proportion of $\mathrm{S}$ phase were observed in the si-lncGHET1 group compared with in the si-NC and control groups in both MG-63 and U2OS cells. Additionally, there was no significant difference among the three groups in $\mathrm{G}_{2}$ phase. Furthermore, western blot analysis was performed to determine the protein levels of relative factors, including cyclin 1, p21 and p27, involved in cell cycle regulation. As shown in Fig. 3C, compared with the si-NC and control groups, the expression levels of p21 and p27 protein were identified to be increased, whereas cyclin D1 expression was revealed to be decreased in the si-lncGHET1 group. Therefore, these data suggested that knockdown of lncGHET1 inhibited cell proliferation in MG-63 and U2OS cells.

Effect of lncGHET1 on development of xenograft tumors in vivo in $O S$. To further confirm the effect of lncGHET1 on the growth of tumors in vivo, MG-63 and U2OS cells transfected with si-lncGHET1 or si-NC were injected into nude mice. As shown in Fig. 4A-D, a significant decrease in tumor volume and weight was observed in the si-lncGHET1 group compared with in the control group and no significant change in body weight was observed. Additionally, H\&E staining was performed to explore the histological alterations of tumors and the results demonstrated that the tissue structure was clearer and more complete in the si-lncGHET1 group than in the control group (Fig. 4E). These results suggested that silencing lncGHET1 expression inhibited the xenograft tumor growth of MG-63 and U2OS cells in vivo.

Effect of lncGHET1 on apoptosis of OS cells in vivo and in vitro. The present study investigated whether lncGHET1 knockdown affected cell apoptosis. The results of a Tunel assay revealed that the number of apoptotic cells was higher in nude mice in the si-lncGHET1 group compared with in mice in the control group (Fig. 5A). Flow cytometric analysis revealed that the percentage of apoptotic U2OS cells was notably increased in the si-lncGHET1 group, with $20.11 \%$ in the si-IncGHET1 group, $10.87 \%$ in the si-NC group and $9.11 \%$ in the control group of U2OS cells. Furthermore, a similar result was observed in MG-63 cells. A notable increase was identified in the si-lncGHET1 group (17.74\%) compared with in the si-NC group (7.51\%) and the control group (7.3\%; Fig. 5B). Additionally, the present study examined several key apoptotic 


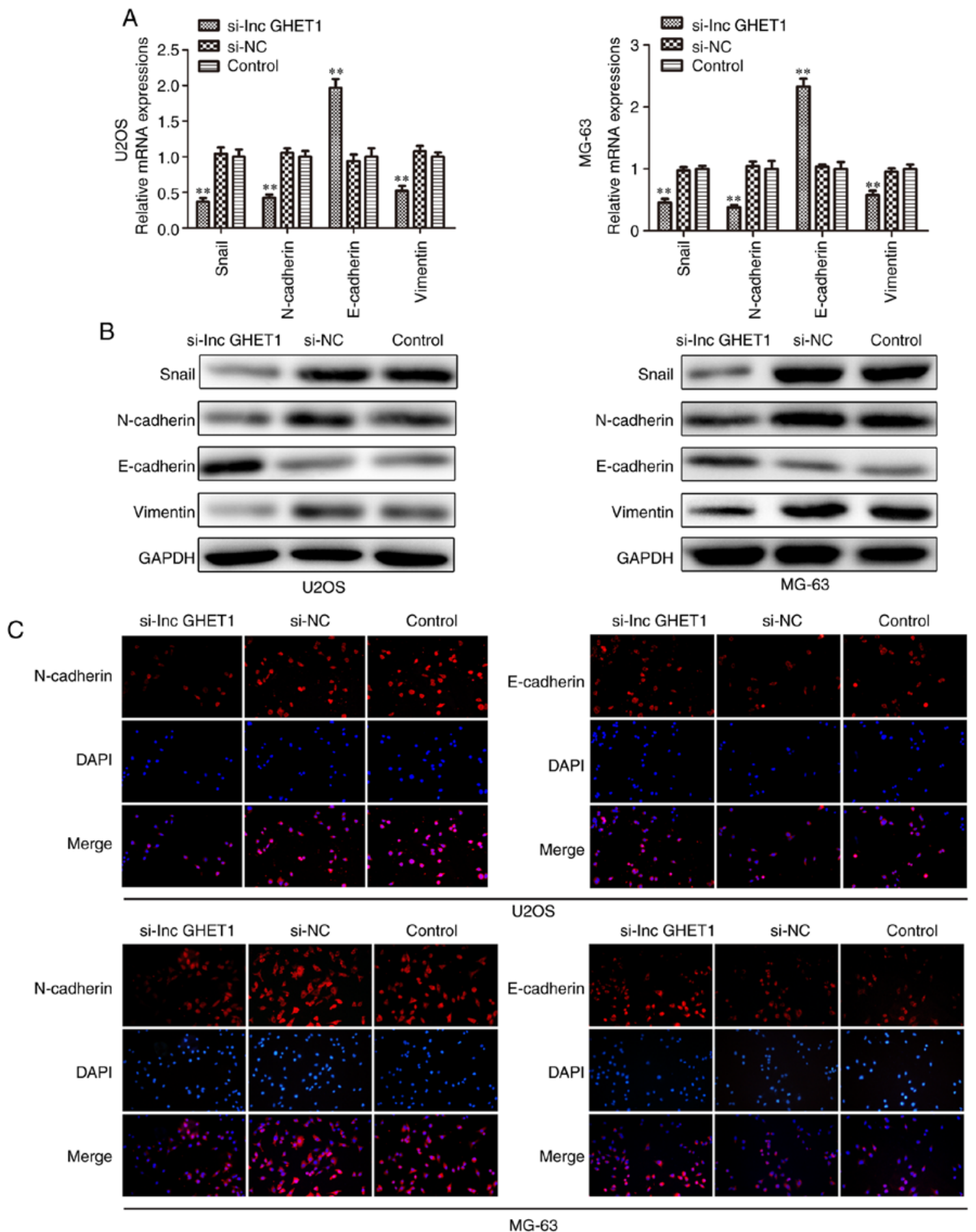

Figure 7. Effect of lncGHET1 on EMT of OS cells. (A-C) EMT-related mRNAs and proteins were detected by (A) reverse transcription-quantitative PCR, (B) western blotting and (C) immunofluorescence assays. Magnification, $\mathrm{x} 200 .{ }^{* *} \mathrm{P}<0.01 \mathrm{vs}$. control group. EMT, epithelial-to-mesenchymal transition; lncGHET1, long non-coding RNA gastric carcinoma proliferation enhancing transcript 1; NC, negative control; si, small interfering RNA.

players in MG-63 and U2OS cells by western blot analysis (Fig. 5C). Compared with the control group, downregulation of lncGHET1 notably increased protein expression levels of Bax, caspase-3 and caspase-9, and decreased the expression levels of $\mathrm{Bcl}-2$. These data indicated that reduced lncGHETlexpression promoted cell apoptosis in MG-63 and U2OS cells.

Effect of IncGHET1 on cell migration and invasion in OS. In order to verify the potential role of IncGHET1 in OS cell migration and invasion, wound healing, and transwell migration and invasion assays were conducted. The results of the wound healing assay revealed that cells migrated towards the wound at a slower rate in the si-lncGHET1 group compared with in the control group (Fig. 6A). In addition, transwell migration assay results indicated that knockdown of lncGHET1 markedly suppressed the migration ability of MG-63 and U2OS cells compared with that of cells in the control group, indicating a decreased migratory ability following lncGHET1 


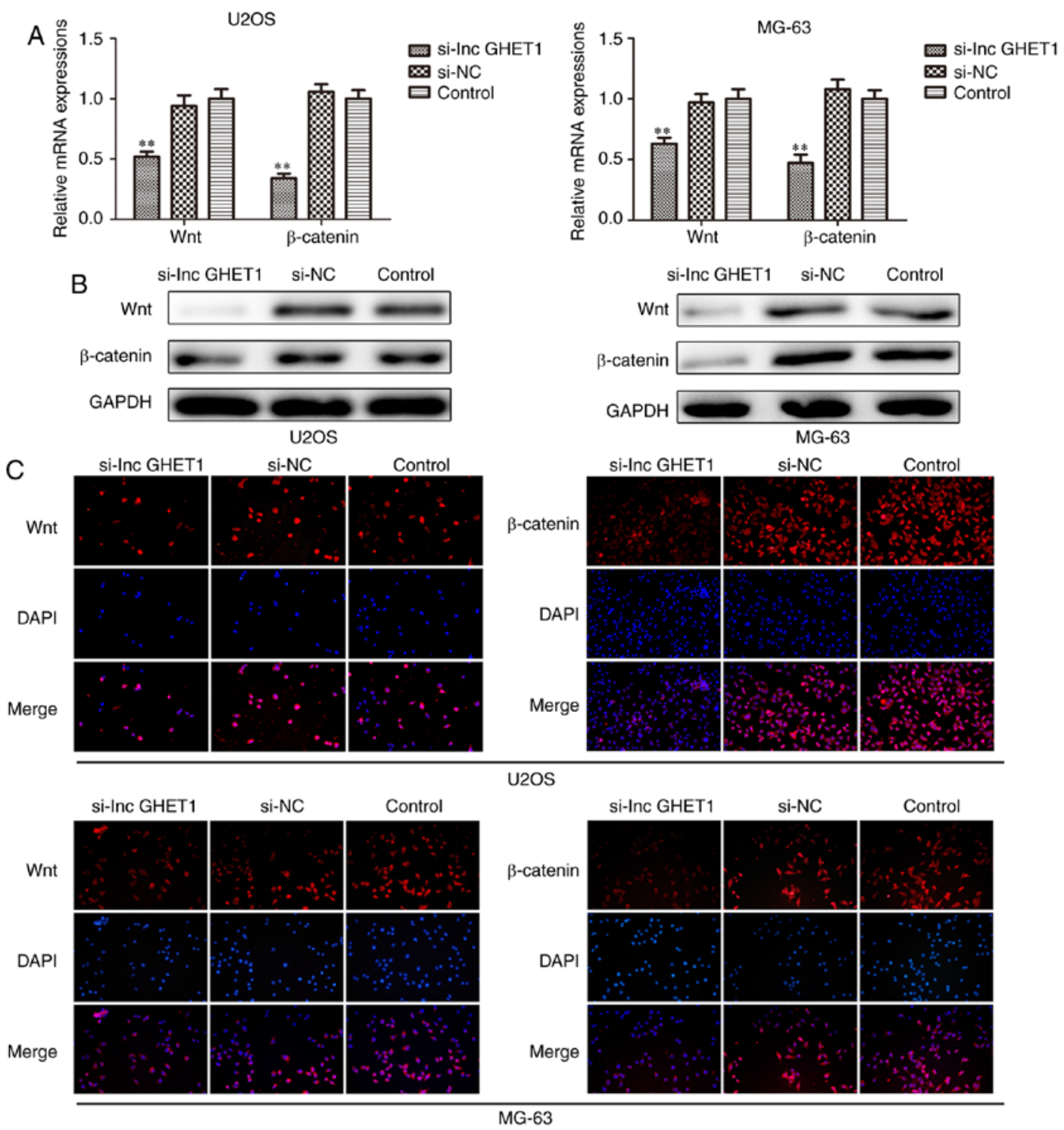

Figure 8. Knockdown of lncGHET1 inhibits cell proliferation and epithelial-to-mesenchymal transition via the Wnt/ $\beta$-catenin signaling pathway. (A) mRNA expression levels of Wnt and $\beta$-catenin were detected by reverse transcription-quantitative PCR. (B) Protein expression levels of Wnt and $\beta$-catenin were detected by western blotting. (C) Protein expression levels of Wnt and $\beta$-catenin were detected by an immunofluorescence assay. Magnification, $\mathrm{x} 200 .{ }^{* *} \mathrm{P}<0.01$ vs. control group. lncGHET1, long non-coding RNA gastric carcinoma proliferation enhancing transcript 1; NC, negative control; si, small interfering RNA.

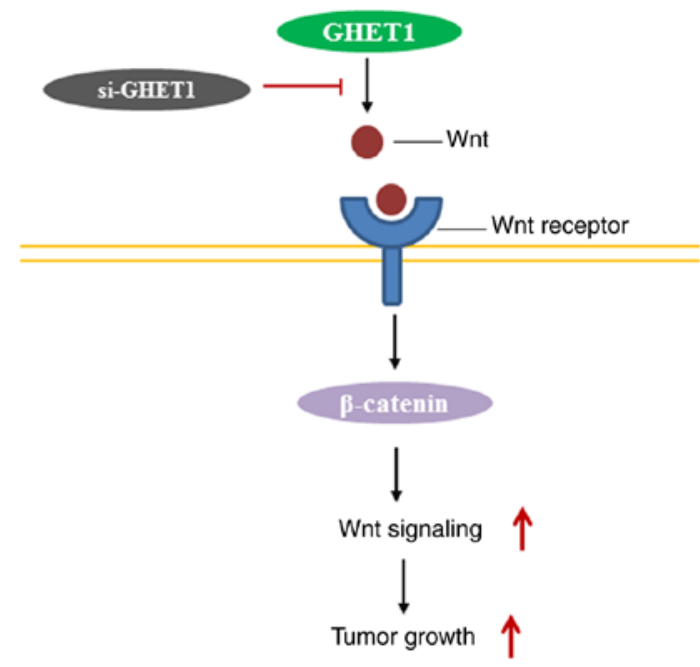

Figure 9. Mechanism of regulation of lncGHET1 and Wnt/b-catenin. GHET1, gastric carcinoma proliferation enhancing transcript 1 ; si, small interfering RNA. downregulation (Fig. 6B). Similarly, transwell invasion assays revealed that the number of invaded cells in the si-lncGHET1 group was lower than that in the control group (Fig. 6B).

Furthermore, western blotting was applied to evaluate the matrix metalloproteinase (MMP)-2 and MMP-9 protein levels. As shown in Fig. 6C, silencing lncGHET1 decreased the expression levels of MMP-2 and MMP-9 in MG-63 and U2OS cells compared with the control group. Therefore, the results suggested that the migration and invasion abilities of MG-63 and U2OS cells were suppressed following lncGHET1 knockdown.

Effect of lncGHET1 on cell EMT of OS. Increasing studies have demonstrated that EMT acts as an important step in metastatic dissemination of cancer cells (24-26) In the present study, the mRNA and protein expression levels of Snail, $\mathrm{N}$-cadherin, E-cadherin and Vimentin were examined by RT-qPCR, western blotting and immunofluorescence analyses. The results revealed that E-cadherin mRNA expression was 
significantly upregulated. The levels of protein expression were also increased, whereas the expression levels of Snail, $\mathrm{N}$-cadherin and Vimentin were downregulated in MG-63 and U2OS cells which were transfected with si-lncGHET1 compared with in cells in the control group (Fig. 7A and B). As shown in Fig. 7C, compared with the si-NC and control group, knockdown of lncGHET1 in the MG-63 and U2OS cells was associated with lower expression of $\mathrm{N}$-cadherin, while the expression levels of E-cadherin remained high.

Knockdown of IncGHET1 inhibits cell proliferation and EMT via the Wnt/ $\beta$-catenin signaling pathway. Furthermore, the underlying mechanism of the role IncGHET1 serves in OS biology was explored. The present study investigated whether lncGHET1 could regulate the proliferation and EMT of OS cells via the Wnt/ $\beta$-catenin signaling pathway. The present study silenced the expression of lncGHET1 in MG-63 and U2OS cells. Subsequently, the mRNA and protein expression levels of Wnt and $\beta$-catenin were detected using RT-qPCR, western blotting and immunofluorescence assays. The results demonstrated that expression levels of Wnt and $\beta$-catenin were decreased following lncGHET1 knockdown when compared with controls (Fig. 8). These data indicated that lncGHET1 exerted its effects in OS partly via the Wnt/ $\beta$-catenin signaling pathway.

\section{Discussion}

OS is the most prevalent primary pediatric bone malignancy in the world (3,27-29). In recent years, advances of modern treatments have been used in the treatment of OS, such as multiagent chemotherapy, surgery and Chinese medical treatments $(30,31)$. However, due to limitations of the effectiveness, the prognosis of OS is still unsatisfactory. The molecular mechanisms underlying the pathogenesis of OS have not been fully explored. Therefore, it is important to elucidate the predictive markers and underlying regulation process in OS.

In recent years, the roles of IncRNAs have attracted immense research interests worldwide. Aberrant expression of lncRNAs has been revealed to be associated with pathogenesis of cancer and other diseases (32-36). Previous studies have revealed that they serve important roles in physiological or pathology processes, particularly in cell growth, tumorigenesis, differentiation and development $(15,37-42)$. However, to the best of our knowledge, the effect of IncGHET1 on the progression of OS remains undetermined.

To investigate the role of lncGHET1 in the regulation of OS, the present study first examined the expression levels of lncGHET1 in OS cell lines. The results revealed that all OS cell lines exhibited relatively high levels of lncGHET1 compared with hFOB cells. The results indicated that lncGHET1 may serve an important role in OS. In the present study, the functional role of lncGHET1 was analyzed in MG-63 and U2OS cells using loss-of-function approaches in vitro and in vivo. The results demonstrated that inhibition of IncGHET1 expression inhibited proliferation, migration and invasion, and suppressed cell cycle progression, whereas it promoted apoptosis of MG-63 and $\mathrm{U} 2 \mathrm{OS}$ cells in vitro and in vivo, indicating lncGHET1 could be an oncogene in OS.
The EMT process contributes to the tumorigenesis (39). Increasing studies have demonstrated the vital role of EMT in cancer invasion and metastasis $(25,43)$. It should be noted that EMT is characterized by loss of the epithelial characteristics, including loss of E-cadherin expression and upregulation of mesenchymal markers, such as vimentin and N-cadherin $(44,45)$. Furthermore, a previous study has suggested that the EMT process is regulated by a set of transcription factors, including Snail, Slug and Twist (46). The present study suggested that suppressing IncGHET1 expression increased the expression levels of E-cadherin. However, Snail, N-cadherin and Vimentin expression was markedly decreased when IncGHET1 was silenced. Additionally, the present study explored the molecular mechanism by which lncGHET1 contributes to tumor progression, and indicated that lncGHET1 exerted an oncogenic effect, partly through regulating the Wnt/ $\beta$-catenin signaling pathway (Fig. 9).

In conclusion, the present study demonstrated that inhibition of lncGHET1 attenuated cell proliferation, migration, invasion and EMT, and promoted apoptosis, partly through regulating the $\mathrm{Wnt} / \beta$-catenin signaling pathway in OS cells. These findings indicated that IncGHET1 may serve as an oncogenic $\operatorname{lncRNA}$ in OS progression, and could be a promising molecular marker for diagnosis and treatment of OS.

\section{Acknowledgements}

Not applicable.

\section{Funding}

No funding was received.

\section{Availability of data and materials}

The datasets used and/or analyzed during the current study are available from the corresponding author on reasonable request.

\section{Authors' contributions}

WF designed the experiments. XC and WZ performed the experiments, and were the major contributors in writing the manuscript. All authors read and approved the final manuscript.

\section{Ethics approval and consent to participate}

All animal experiments were approved by the Ethical Committee of Nanjing Medical University.

\section{Patient consent for publication}

Not applicable.

\section{Competing interests}

The authors declare that they have no competing interests.

\section{References}

1. Cortini M, Avnet S and Baldini N: Mesenchymal stroma: Role in osteosarcoma progression. Cancer Lett 405: 90-99, 2017. 
2. Picci P: Osteosarcoma (Osteogenic sarcoma). Orphanet J Rare Dis 2: 6, 2007.

3. Mckenna WG, Barnes MM, Kinsella TJ, Rosenberg SA, Lack EE and Glatstein E: Combined modality treatment of adult sof tissue sarcomas of the head and neck. Int J Radiat Oncol Biol Phys 13: 1127-1133, 1987.

4. Chen X, Bahrami A, Pappo A, Easton J, Dalton J, Hedlund E, Ellison D, Shurtleff S, Wu G, Wei L, et al: Recurrent somatic structural variations contribute to tumorigenesis in pediatric osteosarcoma. Cell Rep 7: 104-112, 2014.

5. Lian H, Xie P, Yin N, Zhang J, Zhang X, Li J and Zhang C: Linc00460 promotes osteosarcoma progression via miR-1224-5p/FADS1 axis. Life Sci 233: 116757, 2019.

6. Kim W, Han I, Lee JS, Cho HS, Park JW and Kim HS: Postmetastasis survival in high-grade extremity osteosarcoma: A retrospective analysis of prognostic factors in 126 patients. J Surg Oncol 117: 1223-1231, 2018.

7. Fellenberg J, Bernd L, Delling G, Witte D and ZahltenHinguranage A: Prognostic significance of drug-regulated genes in high-grade osteosarcoma. Mod Pathol 20: 1085-1094, 2007.

8. Piperno-Neumann S, Ray-Coquard I, Occean BV, Laurence V, Cupissol D, Perrin C, Penel N, Bompas E, Rios M, Le Cesne A, et al: Results of API-AI based regimen in osteosarcoma adult patients included in the French OS2006/Sarcome-09 study. Int J Cancer 146: 413-423, 2020.

9. Wen J, Qin Y, Li C, Dai X, Wu T and Yin W: Mangiferin suppresses human metastatic osteosarcoma cell growth by down-regulating the expression of metalloproteinases-1/2 and parathyroid hormone receptor 1. AMB Express 10: 13, 2020

10. Zhang Z, Zhao M and Wang G: Hsa_circ_0051079 functions as an oncogene by regulating miR-26a-5p/TGF- $\beta 1$ in osteosarcoma Cell Biosci 9: 94, 2019.

11. Spizzo R, Almeida MI, Colombatti A and Calin GA: Long non-coding RNAs and cancer: A new frontier of translational research? Oncogene 31: 4577-4587, 2012.

12. Yang X, Xie X, Xiao YF, Xie R, Hu CJ, Tang B, Li BS and Yang SM: The emergence of long non-coding RNAs in the tumorigenesis of hepatocellular carcinoma. Cancer Lett 360 : $119-124,2015$

13. Liu Y, Zhang R and Ying K: Long non-coding RNAs: Novel links in respiratory diseases (review). Mol Med Rep 11: 4025-4031, 2015.

14. Yi S, Xiao-jiang Y, Zhen-jun L, Gang L, Wu-jin X and Wei-xia J: UCA1, a long noncoding RNA, promotes the proliferation of CRC cells via p53/p21 signaling. Open Life Sci 11: 206-210, 2016.

15. Maruyama R and Suzuki H: Long noncoding RNA involvement in cancer. BMB Rep 45: 604-611, 2012.

16. Li Z, Yu X and Shen J: Long non-coding RNAs: Emerging players in osteosarcoma. Tumor Biol 37: 2811-2816, 2016

17. Sun J, Wang X, Fu C, Wang X, Zou J, Hua H and Bi Z: Long noncoding RNA FGFR3-AS1 promotes osteosarcoma growth through regulating its natural antisense transcript FGFR3. Mol Biol Rep 43: 427-436, 2016

18. Ruan W, Wang P, Feng S, Xue Y and Li Y: Long non-coding RNA small nucleolar RNA host gene 12 (SNHG12) promotes cell proliferation and migration by upregulating angiomotin gene expression in human osteosarcoma cells. Tumor Biol 37 4065-4073, 2016.

19. Li T, Mo X, Fu L, Xiao B and Guo J: Molecular mechanisms of long noncoding RNAs on gastric cancer. Oncotarget 7: $8601-8612,2016$

20. Li LJ, Zhu JL, Bao WS, Chen DK, Huang WW and Weng ZL: Long noncoding RNA GHET1 promotes the development of bladder cancer. Int J Clin Exp Pathol 7: 7196-7205, 2014.

21. Yang F, Xue X, Zheng L, Bi J, Zhou Y, Zhi K, Gu Y and Fang G: Long non-coding RNA GHET1 promotes gastric carcinoma cell proliferation by increasing c-Myc mRNA stability. FEBS J 281: 802-813, 2014

22. Zhou J, Li X, Wu M, Lin C, Guo Y and Tian B: Knockdown of long noncoding RNA GHET1 inhibits cell proliferation and invasion of colorectal cancer. Oncol Res 23: 303-309, 2016.

23. Livak KJ and Schmittgen TD: Analysis of relative gene expression data using real-time quantitative PCR and the 2(-Delta Delta C(T)) method. Methods 25: 402-408, 2001
24. Pastushenko I and Blanpain C: EMT transition states during tumor progression and metastasis. Trends Cell Biol 29: 212-226, 2019.

25. Huang R and Zong X: Aberrant cancer metabolism in epithelialmesenchymal transition and cancer metastasis: Mechanisms in cancer progression. Crit Rev Oncol Hematol 115: 13-22, 2017.

26. Mittal V: Epithelial mesenchymal transition in tumor metastasis. Annu Rev Pathol 13: 395-412, 2018

27. Wittig JC, Bickels J, Priebat D, Jelinek J, Kellar-Graney K, Shmookler B and Malawer MM: Osteosarcoma: A multidisciplinary approach to diagnosis and treatment. Am Fam Physician 65: 1123-1132, 2002.

28. Isakoff MS, Bielack SS, Meltzer P and Gorlick R: Osteosarcoma: Current treatment and a collaborative pathway to success. J Clin Oncol 33: 3029-3035, 2015.

29. Zhang T, Li J, Yin F, Lin B, Wang Z, Xu J, Wang H, Zuo D, Wang G, Hua Y and Cai Z: Toosendanin demonstrates promising antitumor efficacy in osteosarcoma by targeting STAT3. Oncogene 36: 6627-6639, 2017

30. Liu X, Xiu LJ, Jiao JP, Zhao J, Zhao Y, Lu Y, Shi J, Li YJ, Ye M, Gu YF, et al: Traditional Chinese medicine integrated with chemotherapy for stage IV non-surgical gastric cancer: A retrospective clinical analysis. J Integr Med 15: 469-475, 2017.

31. Zang QQ, Zhang L, Gao N and Huang C: Ophiopogonin D inhibits cell proliferation, causes cell cycle arrest at G2/M, and induces apoptosis in human breast carcinoma MCF-7 cells. J Integr Med 14: 51-59, 2016.

32. Chen LL and Zhao JC: Functional analysis of long noncoding RNAs in development and disease. Adv Exp Med Biol 825: 129-158, 2014.

33. Hajjari M, Khoshnevisan A and Shin YK: Molecular function and regulation of long non-coding RNAs: Paradigms with potential roles in cancer. Tumour Biol 35: 10645-10663, 2014.

34. Gupta RA, Nilay S, Wang KC, Kim J, Horlings HM, Wong DJ, Tsai MC, Hung T, Argani P, Rinn JL, et al: Long non-coding RNA HOTAIR reprograms chromatin state to promote cancer metastasis. Nature 464: 1071-1076, 2010.

35. Takayama K, Horie-Inoue K, Katayama S, Suzuki T, Tsutsumi S, Ikeda K, Urano T, Fujimura T, Takagi K, Takahashi S, et al: Androgen-responsive long noncoding RNA CTBP1-AS promotes prostate cancer. EMBO J 32: 1665-1680, 2013.

36. Zhao H, Zhang K, Wang T, Cui J, Xi H, Wang Y, Song Y, Zhao X, Wei B and Chen L: Long non-coding RNA AFAP1-antisense RNA 1 promotes the proliferation, migration and invasion of gastric cancer cells and is associated with poor patient survival. Oncol Lett 15: 8620-8626, 2018.

37. Ernst $\mathrm{C}$ and Morton $\mathrm{CC}$ : Identification and function of long non-coding RNA. Front Cell Neurosci 7: 168, 2013.

38. Wang KC and Chang HY: Molecular mechanisms of long noncoding RNAs. Mol Cell 43: 904-914, 2011.

39. Tam WL and Weinberg RA: The epigenetics of epithelial-mesenchymal plasticity in cancer. Nat Med 19: 1438-1449, 2013.

40. Van Der Steen N, Honeywell RJ, Dekker H, Van Meerloo J, Kole J, Musters R, Ruijtenbeek R, Rolfo C, Pauwels P, Peters GJ and Giovannetti G: Resistance to crizotinib in a cMET gene amplified tumor cell line is associated with impaired sequestration of crizotinib in lysosomes. J Mol Clin Med 1: 99-106, 2018.

41. Liu H, Zhao J and Lv J: Inhibitory effects of miR-101 overexpression on cervical cancer SiHa cells. Eur J Gynaecol Oncol 38: 236-240, 2017

42. Hu H, Zhang G, Tian G, Lv G and Jin Y: miRNA profiling reveals the upregulation of osteogenesis-associated miRNAs in ovariectomy osteoporosis mice. Clin Exp Obstet Gynecol 45: 817-822, 2018.

43. Pan JJ and Yang MH: The role of epithelial-mesenchymal transition in pancreatic cancer. J Gastrointest Oncol 2: 151-156, 2011.

44. Gonzalez DM and Damian M: Signaling mechanisms of the epithelial-mesenchymal transition. Sci Signal 7: re8, 2014.

45. Ye X and Weinberg RA: Epithelial-mesenchymal plasticity: A central regulator of cancer progression. Trends Cell Biol 25: 675-686, 2015

46. Nieto MA: Epithelial plasticity: A common theme in embryonic and cancer cells. Science 342: 1234850, 2013. 